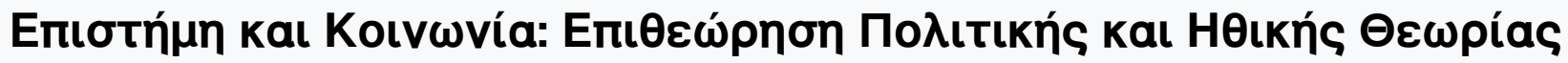

Tó 30 (2013)

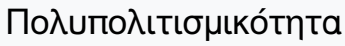

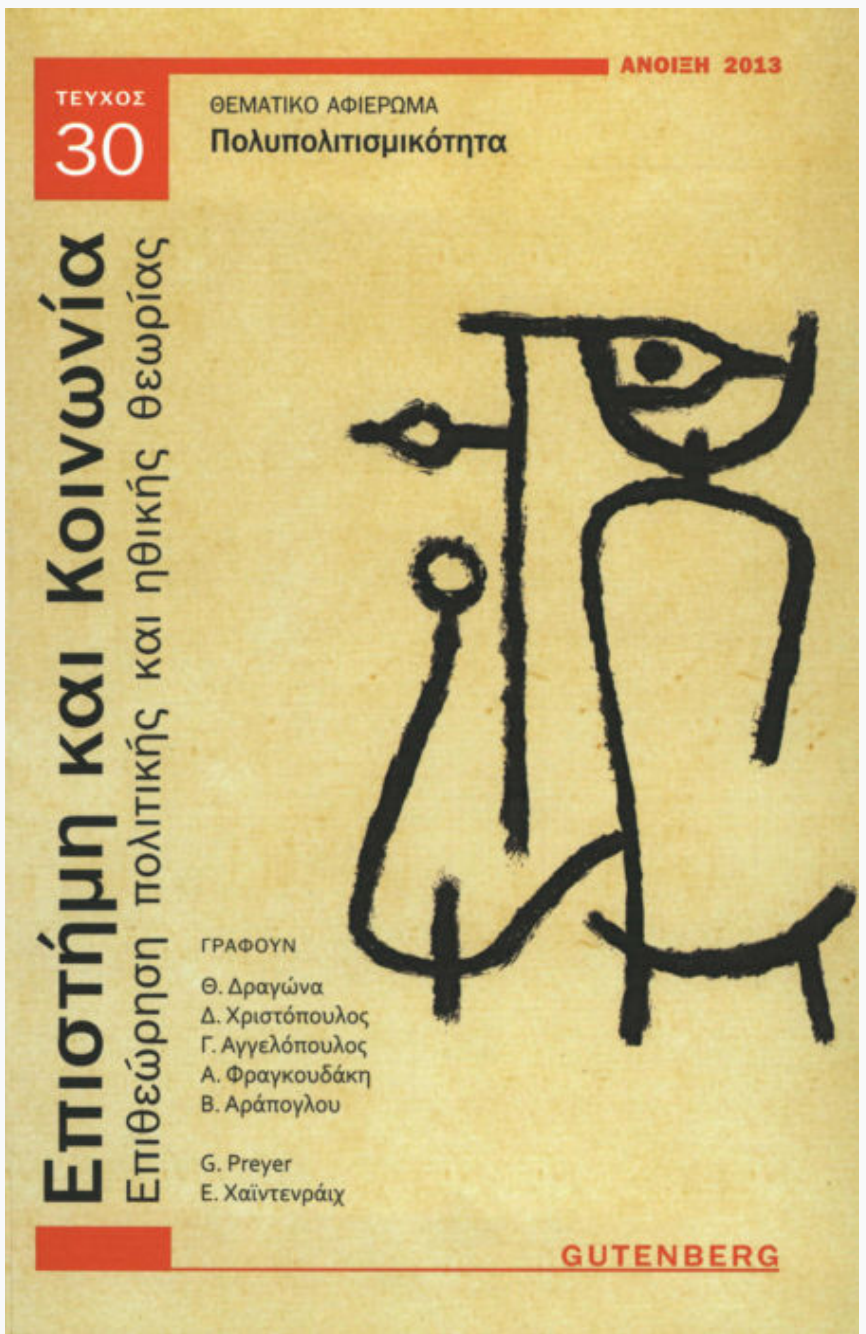

The perspective of multiple modernities on Shmuel N. Eisenstadt's sociology

Gerhard Preyer

doi: $10.12681 /$ sas. 647 


\section{Gerhard Preyer*}

\section{THE PERSPECTIVE OF MULTIPLE MODERNITIES ON SHMUEL N. EISENSTADT'S SOCIOLOGY}

Shmuel N. Eisenstadt has modified the classical theory of modernization in principle. In the history of his work which is connected with the changes of sociological theory since the 1950 s he has made a turn from the comparative analysis of institutions to the research program of comparative civilizations. The research program of multiple modernities has emerged out of this shift of attention. This led him to the critique of the theory of structural differentiation as the main process underlying the socio-structural evolution of societies and the convergence theories of modernization which have taken effect in contemporary sociological theory. The article reconstructs Eisenstadt's theoretical sociology and his analysis of institution building. It interprets his research program of multiple modernities and the function of Axial-civilization in the structural evolution in this framework.**

* Professor of Sociology at the Goethe-University, Frankfurt am Main, publisher of ProtoSociology. An International Journal of Interdisciplinary Research and Project, <preyer@em.uni-frankfurt.de>.

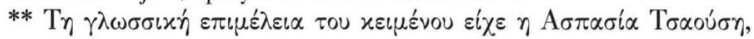

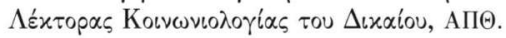


Not only multiple modernities continue to emerge - by now going beyond the premises of the nation states-but within all societies, new questionings and reinterpretations of different dimensions of modernity are emerging. [...] All these developments do indeed attest to the continual development of multiple modernities, or of multiple interpretations of modernity - and, above all, to attempts at 'de-Westernization,' depriving the West of its monopoly on modernity (Eisenstadt 2003b: 559).

Shyuel N. Eisenstadt was one of the leading figures in sociology since the 1950s. There is no single sociologist whose research and theorizing has carried on for nearly 60 years. He has contributed significantly to the formation of the sociological theory from the beginning of his career. Eisenstadt has established since the mid-1970s the research program of comparative civilisations and has conducted research on it at the Department of Sociology and Social Anthropology of the Truman Research Institute (Hebrew University, Jerusalem). Overall, his sociological work and his intellectual career is characterized by a shift, in the context of sociological theory, from the comparative analysis of institutions to the research program of comparative civilisations. ${ }^{1}$ This step led him to a critique of the classical theory of modernization using the research program of multiple modernities. The so-called classical theory characterized the modern social structure and its cultural program by the tendency of structural differentiation of the economic, political, scientific, religious, educational subsystems of the society, a process which goes along with urbanization, particular channels of communication and a strong individualistic lifestyle.

The social structure was established as it shifted from the medieval European civilization, politics, and economies to the

1. On a self-description of his intellectual history in the context of sociological theory, see Eisenstadt 1995: 1-40, 2003a: 1-28. On the reconstruction of Eisenstadt's work in the context of changes of the sociological theory since the 1950s years, see Preyer 2011: 13-57. 
modern society in particular after the French Revolution. The view was that this program and structure would be adapted by all modernizing societies ultimately by the expansion of the pattern of Western modernization. This was prevalent in the development theories and the convergence theories since the $1940 \mathrm{~s}$, and especially until the 1960 s, a period which was characterized by an optimistic attitude about the success of the Western model of modernization. ${ }^{2}$ It assumed that a convergence of the industrial societies of the open (Western) and the closed societies (Communist regimes) will happen, that is, modernization is not only a diachronic but also a structurally synchronic process. It was a new, optimistic view of modernity and of the chance to be successful with the Western modernization. Parsons assumed that evolutionary universals for re-interpretating modernization are not only caused by the global expansion of modernity in different cultural spheres of the emerged so-called world society, but are also developed under particular internal societal conditions. $^{3}$ R. Bellah, for example, analyzed the Togugawa regime and society as a functional equivalent to the role played by Ascetic Protestantism in the modernization of Old Europe (Bellah 1957). For the classical theory of modernization, the Japanese society and the changes of their social structure in the Meiji Restoration were the counterexample of its confirmation. ${ }^{4}$ But from the beginning of the worldwide expansion of modernity, the question became whether modernization culminates in a homogenous or a heterogeneous civilization and world culture.

Eisenstadt's theoretical shift in the theory of modernization is a contribution to a systematization of the socio-structural evo-

2. On the view of the classical theory of modernization Black 1966 , Levi 1966, Weiner 1966. On a critique of development theories, Nederveen Pieterse 2001.

3. On evolutionary universals, see also, Parsons 1967: 490-520

4. See, for example, among other studies, Eisenstadt 1989: 125-140, 1990: 25-35; in Eisenstadt 1994: 63-95, he concludes from his investigations that Japan is a worldwide unique society. 
lution of societies. The core of his sociology which goes back to his student days is the analysis of the relationship between power, trust, and meaning as the basic-problem of social order, conceived as an 'order' which is imperfect and fragile. But he does not conclude from the point of view of this critique of the classical theory of evolution and its assumption of the structural differentiation as impetus of the evolutionary change, that in the sociological theory the analysis of structural change is not fruitful. From his point of view the socio-structural evolution happens as a variation of structures. His particular sociological question and his research on the structural evolution of societies emerged in the context of the changes in sociological theory after the Second War; it was this that he took apart and reshaped.

Eisenstadt's general sociology is an analysis of the framework of the relationship between agency (creativity) and structure and between culture and social structure (macro-order of a society) as the cantus firmus of his sociological research and the leading question of sociological theory since the 1950s as well. From Eisenstadt's point of view, a society is a collectivity which imposes constraints on its members as a prerequisite for participation in the social intercourse. There is no society without the collective identity of its members. Collective identities are not residuals, as some theorists of modernization in the $1950 \mathrm{~s}$, for example, G. Myrdal and other contemporary sociologists have argued (Myrdal 1998 [1944]). They do not disappear in the change of socio-structural evolution and modernization. Social change is conditioned by the construction of the conditio humana - the cosmological and ontological belief systems- which dominate all societies and communications.

The result of his research is a new analysis of the relationship between culture and social structure. This takes effect in the understanding of social order because socio-structural evolution is at the same time an order-transforming and ordermaintaining process. From the contemporary sociological theory perspective, this problem is affirmed by the new version of 
the theory of social integration. ${ }^{5}$ Firstly, I sketch the core of Eisenstadt's theoretical sociology, that is, the problem of structure and the function of the semantic map. Secondly, this leads me to Eisenstadt's analysis of institution building and his critique of the evolutionary theory of structural differentiation. Thirdly, I will refer to his characterization of the Axial civilizations as impetus of multiple modernities in socio-structural evolution.

\section{Structure and the Semantic Map}

(a) The Problem of Structure

The majority of sociologists agree that social evolution is an abbreviation of processes of social structural change. The mechanisms of social change are the subject of sociological theory and transdisciplinary research. Eisenstadt has accepted the basic implication of the classical theory of evolution of human societies that populations have a strong tendency to expand (Eisenstadt 1998: 29-30). The impetus for structural evolution is an expansion and the decoupling of different dimensions of social action from the framework within which they are embedded and from one another as well (differentiation), which is confirmed by different disciplines of evolutionary research such as sociology, economics, cultural anthropology, and population theory.

Eisenstadt has investigated the properties of the development in different dimensions of such expansions and differentiation in the process of evolutionary change and its breakthrough. He gives a particular analysis of structural differentiation, social order and the belief systems (M. Weber: Weltbilder/worldviews) of the pressure groups as a critique on the presuppositions of classical evolutionary and structural-functional analyses. The core

5. In my point of view, a switch has been made in the meantime in the theory of social integration. On the structural question of social integration and the fields of research, see Preyer 2006: 289-311 and 2008: 217-267. 
of his version of evolutionary differentiation is that the link of the decoupling of structural and symbolic dimensions is the decoupling of the basic elites. Eisenstadt concludes from his investigation that social change is not a natural event and is not caused by the prevalent ontologies of the civilizations and by social structure itself, but by the 'interweaving' of the cultural and social structural dimensions in concrete situations. This takes effect in our understanding of structural evolution and history.

Social systems are boundary-structured entities which have a particular epistemological and ontological status because they exist in the communications of their members only. They are not parts of their environment. Their differentiation from their environment goes along with structures. There is a specific relationship between structure and agency because the "basis of human agency' is constituted by the construction of structure which generates hegemonic power and the access to resources of different groups (Eisenstadt 1995: 360-361). ${ }^{6}$ Structures are restrictions of communication. The structure and structuration of the social interaction and their contribution to the socio-structure as the macro-order of a society is determined by the basic borderline that divides inside from outside social interaction. Human agency and agent activities - in this point Eisenstadt agrees with A. Giddens- reproduce and transform at the same time a society by structuration (Eisenstadt 1995: 21). ${ }^{7}$ Eisen-

6. He goes along with Sewell's (1992: 1-29) analysis of the duality of structure as schemas which have a 'virtual' existence and of actual resources.

7. Eisenstadt reviewed Giddens' concept of structuration and argues that the merit of his analysis is a critique of a reification of structure which was conceived among many sociologists but 'he (Giddens) did not distinguish sharply enough between different levels of structuration especially between the structuration of activities which are within given institutional frameworks, those through which such frameworks are constructed and between levels or types of systemic tendencies in different levels and patterns of social interaction' (Eisenstadt 1995: 21). See on structuration, Giddens 1979,1984 . The question of sociological theory from the point of view of the 1970 s was the problem of the relationship between structure and event respectively between agency (communication) versus structure. Structures are 
stadt systemizes socio-structural evolution as variations of structures because the framework of agency and communication is created by human agency and at the same time agency and communication is possible by frameworks (structure) only. ${ }^{8}$

Thus, in a sense, such structures, or the tendency to such structuration, constitute what has been called the "evolutionary universals' of any known society. They constitute the basic frameworks within which any action takes place. But their concrete specification continuously changes in history through processes of interaction which develop within such frameworks. Such processes which entail the interweaving of the concrete parameters of these frameworks change, but not the general tendency to the structuration of human activity within them. (Eisenstadt 1995: 389).

Therefore the functional imperative of the reproduction of social systems are structures. ${ }^{9}$ These are "preconditions' -as Eisenstadt calls them- which are to be fulfilled by the members of a society who have, as members of this society, to perform particular roles. This precondition explains the role of authorities and power in all societies. ${ }^{10}$ Let us call that the problem of structure. The preconditions are embedded in the conflicts and change in every society. The key of the analysis of the construction of structure is that its construction generates hegemonic

restrictions of expectations and their regulations which are determinated by conditions of membership in social systems. From Giddens' and Eisenstadt's point of view structures are not just expectations but they also determine that members of social systems have resources at their disposal. In my point of view, this is in harmony with the sociology of membership. On this problem, see Preyer 2011: 72-75.

8. On the structural evolution of the societal system and the evolution of the code of membership by the differentiation of the ascriptive solidarity and its restructuration, see Preyer 2008: 61-126, 1998: 71-123.

9. Structures are to analyse as expectations (of expectations) and their regulations which are determined by conditions of membership in social systems.

10. On the role of these functions in primitive societies, see Eisenstadt 1971: 77-83. 
power which elites dispose about the free resources. The access to the production and the flow of resources is the core of human agency. But the conflicts and potentialities of change differ by the particular development within societies and civilizations.

From Eisenstadt's point of view, the basic feature of sociostructural evolution is the internal indeterminacy of the continuation of societal communication. Call that the initial evolutionary situation of structural evolution. Following E. Mayer, he explains the indeterminacy by the openness of the biological human program (Mayer 1976). ${ }^{11}$ The boundaries are not determined by the genetic program. They are constituted through communication and its structure. The indeterminacy is inherent in all human activities; therefore the relationship between the goal orientation of participants to communication, the resources they can dispose of and the organization of communication generates the major problem of filling the open space by general propensities and their specification. Call that the initial evolutionary situation or system of structural evolution. Eisenstadt's sociology is therefore a sociology of social space:

The existence -in all areas of human action- of open spaces between the general propensities of human beings and the concrete specifications of these propensities means that the crux of concrete human activity is the 'filling in' of such spaces. Such 'filling in' can be effected only through social interaction, which however, is also characterized by indeterminacies and open spaces, which begins with the processes of the socialization of the young and continues through the adult life of members of societies (Eisenstadt 1995: 331).

This indeterminacy is the foundation of all social interactions and their continuation in time. The limitation of the indeterminacy and the shaping of open spaces require, as a functional imperative, the construction of trust, solidarity, legitimation, meaning and the regulation of the use of power. Eisenstadt has in-

11. See also Eisenstadt 1995: 330. 
vestigated this question by the interplay of agency (creativity) and structure, culture and social structure in the socio-structural evolution. In this framework he considers the role of charisma in institution building and social order: 'The essence of the charismatic dimension of human life is the attempt to reach the very essence of being, to go to the very roots of existence, of the cosmic, cultural, and social order, to what is seen as sacred and fundamental' (Eisenstadt 1995: 312). ${ }^{12}$ The charismatic dimension has as intrinsic property: both a constructive and a destructive potential. But the awareness of the indeterminacy of the members of the social system causes the experience of contingency of the given social order.

Eisenstadt makes the assumption that the main question of the sociological theory since the 1950s was the analysis of the relationship between social structure, culture, and social change. The background of this analysis is the problem of creativity.

The problem of such creativity and the closely connected problem of the potential range of human freedom in social contexts, have recently re-emerged in theoretical discussion in the social science as the problem of human agency in relation to social structure. This problem was, of course, already central in classical sociological theory (Eisenstadt 1995: 1).

The charismatic dimension of agency is incorporated in human freedom and creativity. The latter, which is involved agency, also causes an increase of autonomy and a tendency of differentiation of agency from social contexts. This continuously provokes particular strains in the social structure.

Eisenstadt investigates the relationship between culture and social structure as analytical components of communication, interaction and creativity of the members of a society. The components are so-called 'interweaved'. The process of socio-structural differentiation involves some agents being in a position to

12. Eisenstadt continues the approach of Weber \& Shils 1975. See Eisenstadt 1995: 167-201. 
control other members of the society by their independency from the ascriptive social organization and by the disposition of means of power. This takes effect in the 'deep structure' and the 'negotiated order' as well. The connection between both of them is the question how to convert the cultural visions and orientations in the basic premises of civilization and the political and social order. These premises specify the relation between the social division of labor, the regulation of the use of power, the construction of trust and meaning which are articulated and spread by various elites. ${ }^{13}$ This is realized by different mechanisms of the symbolic and institutional control. These are the basic premises of social order and the basic institutional sectors and formations which constitute the 'deep structure' of a society. Eisenstadt concludes that the organization of the division of labor and market mechanisms are inadequate when explaining the construction and maintenance of social order, like the founding fathers of sociology have assumed.

The institutional processes and mechanisms take effect in the structure. The cognitive and evaluative schemes organize behavior in social systems. They are not only purely cognitive, but are connected with the problem of the existence of human life and social organization. Eisenstadt counts within this existential foundation the self-awareness and the reflexivity and problematization which emerges as meta-thinking. The central focus of this reflexivity is the recognition of the arbitrariness and contingency of the social order, and social orientations which generate a certain ambivalence toward this order.

Eisenstadt characterizes this foundation thus:

Human self-awareness, the construction of meaning and reflexivity, and the tendency to meta-thinking in all human societies does not take place in an entirely random way, even if such con-

13. Eisenstadt's concept of elites is to distinguish from V. Pareto's concept of circulation of elites, see, Ben-Rafael \& Sternber 2005: 4370-4. They emphasize that Eisenstadt investigates the role of elites in social contexts an in social (historic) change. 
struction is not predetermined in all its details either by the genetic endowment of the human species (as suggested by some sociobiologists) or by the constant rules of the human mind (as implied by many structuralists). Such 'construction of meaning' is structured through the cognitive schemata referred to above. Such schemata are first of all constituted according to distinct parameters of structuration which are to be found -as the structuralists have stressed in their Kantian orientation- in all societies or cultures. On the most general level, such schemata are structured around the categories of time, space, and the self-reflecting subject in relation to different objects to the environment. A central aspect of such human self-reflection is the fact that the subject also constitutes an object of such reflection (Eisenstadt 1995: 339).

The central functional imperative of social units is the maintenance of their inside-outside differentiation. The basic concept of Eisenstadt's frame of reference of the analysis of social systems and their structure is the concept of boundary. Boundaries are constitutive for the self-selection of social systems. But at the same time the structure maintenance causes conflicts and contradiction which may lead to change, transformation, or decline and to the reconstruction of modes of boundaries of social systems. 'The construction of the boundaries of social systems, collectivities, and organizations necessarily delineates their relations with their environment. However, it is wrong to assume that there is a natural environment of any society, of pattern of social interaction. There is no such thing as the 'natural' environment "out there" (Eisenstadt 1995: 358-59). From Eisenstadt's perspective, the environment of social systems does not determine their structure and organization because there are variations of their social structure. The social universe has systemic properties, that is, it is delineated by the basic borderline between inside and outside. This boundary of social systems is to be established by restrictions only. Collective identities, institutions, and organizations are such restrictions which are recreated in social change continually. These identities are encoded by the condition of membership. 
The analysis of collective identities is not the traditional one -that is, to describe such identities with natural properties-, but to describe them as constructions and imaginary entities. Eisenstadt and B. Giesen have distinguished the primordial, like gender, generation, kinship, territory, language, race, the civic, like implicit and explicit rules, traditions, social routines, and the sacral/transcendent code, like the relation of the collective subject to the sacred and sublime (defined as God, Reason or Progress) (Eisenstadt \& Giesen 1995: 72-102, Eisenstadt 2009: 135-184). The construction of collective identities and the selection of membership is not without continual tensions, conflicts and contradictions. Sociologists analyze this as a self-awareness of the social, caused by the self-selection of social systems and the recognition of their borderlines by their members. Collective identities and the mechanisms of their stabilization are labeled by the distinction between member and non-member (strangers) as their elementary encoding. In the West, the conflict between citizenship and membership of a primordial community, state and nation is a classical one. Collective identities and their construction and re-interpretation are the link between structure, culture, and social structure. They constitute the manifestation of social order and charismatic activity and are related to basic cosmology.

\section{(b) The Semantic Map}

Eisenstadt makes a new turn in the analysis of the relationship between culture and social structure. The relationship between them is analyzed in the depiction of the semantic map as it is formed by two poles (axes):

1. The first pole depicts the problematic of the definition of the cosmological order and its relationship to the world, which reconcile the difference between mundane world and transcendental sphere. The answer that is provided refers to a society's way of life. The impact of the institutionalization of the basic 
premises of cultural orientations and programs and their reproduction is shaped by the major elites and their modes of communication and control.

2. The second pole is the social universe within which conflicts and tensions are generated by the structuring of the social interaction through the definition of the cosmological order and its symbolic construction.

The construction of the semantic map of the basic tradition or premises of societies or sectors thereof entails the specification of the definition of the legitimate range of problems related two basic axes, the ways in which these problems and answers to them are formulated, and their legitimation in terms of the range of meta-meanings. It entails their major institutional implications, and their transformation into the basic premises of the social order, i.e. the specification of the relation between the basic dimensions of social order alluded to above - namely the division of labor, of trust, of boundaries of collectivities, regulation of power, the construction of meaning of human activities in terms of these basic poles and axes, and their institutional implications (Eisenstadt 1995: 298).

Therefore, Eisenstadt's sociology claims to offer a frame of reference for the systemization of the relationship between power, trust and meaning as the basic problem of social order in the constellations of socio-structural evolution.

The indeterminacy of the processes of communication consists of the relationship between 1. the membership of society and its collectivities, 2 . the goals of the members of a society and 3 . the goals of the members of a society and the resources they have at their disposal. Awareness of indeterminacy refers to the construction of the social order as a component of the self-interpretation and self-awareness of the members of a society.

All societies construct such a social and cultural order, designed in part to overcome the uncertainties and anxieties implied in these existential givens. They do so by constructing symbolic boundaries of personal and collective identities (Durkheim), by defining mem- 
bership in different collectivities in terms of universal biological primordial categories such as age, generation, sex and territorial attachment, by 'answering' certain perennial problems of death and immortality in religious belief systems, and by distinguishing between the given, mundane world and another world beyond it and between the profane and the sacred (Eisenstadt 1995: 310).

Uncertainties and anxieties constitute pre-dispositions for the construction of the sacred search for a meaningful world which at the same time constructs the access to the established cosmological and social order. The construction of the domain of the sacred is the core of human charismatic activity. This core establishes access to the cosmological order. This is at the same time the quintessence of revolutionary situations.

The basic semantic maps determine the central problems of human and social existence, the specification of their solution and the relationship to the basic assumptions of social order.

A very central aspect of the crystallization of the institutionalization of the semantic map of a society, sectors thereof, or of individuals, is the symbolic, ideological definitions of the basic premises of different spheres of human activities and of social sectors in general, and of the political sphere in particular. It is these definitions of these premises that provide such activities with their specific meaning and legitimation in the respective societies or sectors thereof. Such symbolic definitions of economy of polity, and the like, need not be identical with their structural differentiation. These spheres do not have to be designated in symbolically distinct autonomous ways in every society with a relatively differentiated and specialized economic or political order (Eisenstadt 1995: 298-299).

The basic premises of civilizations and the expectations determinate the borderlines of collectivities. They are conditions for the membership in a society which also fix the ethical rules and the criteria of justice. The link between the division of labor and its role set and regulation of the flow of resources are ground rules. They specify 1 . the symbolic boundaries of collec- 
tivities, 2 . access to the resources and their regulation, 3. establishment of rights and obligations, and 4. the meaning of collective goals (Eisenstadt 1995: 344-345). The reinterpretation of the ground rules and concomitant institutional framework constitute foci of human agency and the charismatic dimension of human activity in the domain of social interaction. Eisenstadt investigates the question as the relationship between structure, social structure and agency (creativity). The social structure has pre-conditions and these are restrictions of the creativity of the members of society. These pre-conditions constitute the structure of the social interaction in a society. This is the focus of the analysis of the relationship between social structure and agency.

The preceding analysis indicates the nature of the relation between 'social structure' and 'human agency'. The preceding analysis indicated that structure is basically the specification of access to 'symbolic' and material' resources, of their use, and of the possibility of the conversion between such different resources, i.e. between economic resources, power and prestige, and information. Such conversion, according to the different schemata, is grounded in the various code-orientations. It is the specification of these code-orientations through the interaction between elites, influential, and broader sections of society that transforms some 'objective' human or natural givens into resources which can be used in social interaction. ... The construction of structure creates hegemonic power which enables the use of resources by different people, but at the same time, it also empowers all those connected to it in respect to such access. It is such access to resources that constitute the core of basis of human 'agency' (Eisenstadt 1995: 359-360).

The institutional setting is composed in particular by the following: 1. the conceptions of visions or cultural orientations which are dominant in a given society, 2. the major elites, that is, the institutional entrepreneurs who mobilize and structure the resources, and 3 . the distribution of resources among various societal groups with respect to the structure of the social division of labor. 
Every social order and pattern of social interaction is determined by the symbolic dimension of human activity, and in particular by a basic cultural and ontological vision. The restriction of creativity is generated by the structure of institutionalization and its specialization of social roles which constitute a selection from a range of imagined possibilities. In the case of the charismatic authority, creativity leads institutionalization to routinization (M. Weber Veralltäglichung). Eisenstadt has investigated this question since the 1970 s using as his example the role of protest in Axial civilizations and the relationship between the great revolutions and Western modernity (Eisenstadt 1978). ${ }^{14}$

\section{Institution Building and the Critique on Structural Differentiation}

\section{(a) Component of Institution Building}

The basic semantic maps pair the function of charisma and its institutionalization, the centrum-periphery-relationship and the symbolization of the collective identity of the members of a society to the sectors within the institutionalization takes place. Eisenstadt distinguishes as components of institution building:

1. The type of cosmological order which is the foundation of the cultural orientation of a society. ${ }^{15}$ The cosmological order is implemented as the basic institution of the order of kinship, law, and religion. This order contributes to the formation of center-periphery constellation and to the charismatization of the center, as well as to the formation and stabilization of the collective identity. Eisenstadt emphasizes:

14. For a summary of his investigations, Eisenstadt 2006a.

15. Eisenstadt distinguishes between an innerworldly and outer(other-) worldly orientation (M. Weber). But the distinction is not to generalize. This is shown by M. Ames' research on religious movement in Buddhist Ceylon, Eisenstadt 2006b: 111-112. 
It is this double aspect of social institutions -their organizational exigencies on the one hand, and their potentially close relation to the realm of meaning on other- which may provide us with clues as to how the ordinary and the charismatic are continuously interwoven in the process of institution building. New organizations and institutions are built up through the varied responses and interactions between people or groups who, in order to implement their varied goals, undertake processes of exchange with other people or groups (Eisenstadt 1995: 188).

Therefore: by the institutionalization of the charisma and the center-periphery-relationship societal formations are build which are continually reconstructed in the socio-structural evolution.

2. The elites and institutional entrepreneurs which mobilize, organize, and distribute the free resources. ${ }^{16}$

The impact of such premises (of the cosmological order) and their institutional derivatives on the formation and reproduction of institutional formation is effected through the activities of the major elites by various mechanisms of social interaction in general and of control in particular as well as by development of challenges to such control that develop among such elites and broader strata of the society or sectors thereof (Eisenstadt 1995: 297).

It is this function of the elites that connects the structural and cultural processes which have not only a task in the social division of labor, but also provide an answer to the problem which was caused by structural differentiation, like, for example, the forming of trust, the regulation of power and meaning. This initiates a crystallization of different institutional structures and the modes and levels of the distribution of free resources among the social groups. This has to take in the analysis of the

16. On the concept of 'free resources', see Eisenstadt 1963. Entrepreneurs (elites) are active groups which give solution to the range of new problems. Resources are manpower, money, political support, or religious identification. 
social division of labor and of institutionalization. The distinction between structural differentiation and the functions of elites leads Eisenstadt to a critique on the classical theory of evolution as a development theory.

3. The process of institutionalization has no final end in principle. The social order is not perfectible by the open biological program and the evolutionary emerging forms of the division of labor and differentiation generate uncertainties among the members of society. This is because the allocation of resources, the access to power and to social status positions, as well as the solidarity within institutions and organizations is not a pre-regulated socio-structural process. This is also the case when communication and expectations are regulated by organizations and the differentiation of social roles. Eisenstadt pays particular attention to the relationship between meaning and social structure because all members of social systems are confronted with the symbolic outline of order (meaning) as orientation of their social interaction. This problem is dramatized because symbols lack an unambiguous reading. They are ambiguous and can be interpreted differently, for example, justice, equality and social solidarity. This ambiguity of readings generates again and again uncertainties, conflicts and social change.

Charisma and center connects the symbolic and cosmological orientation and thereby the access to and the disposition of free resources. The center is the social place of the socio-structural connection between order, power, justice, solidarity and the social division of labor. The elites at the center do not only dispose of free resources, but also determine by the charismatic order the prestige of the members of society. Eisenstadt emphasizes that the social order is not a specialization of role and the distribution of resources by institutions only. The social order is based on prestige (honor) (Eisenstadt 1995: 239-279). The precondition of societies and the prestige of the members of social systems play a joint role as the specifications of membership conditions. 


\section{(b) The Critique on Structural Differentiation}

One of the main results of Eisenstadt's research since the 1950s was his critique on the structural theory of differentiation. From the Parsons-Durkheim tradition the differentiation of social structure generates a new problem of social integration. The functional imperative of the solution of this problem is the integration of the members of society within new subsystems and the regulation of the membership in these social units. The focus of social integration is for Parsons the so-called normative complex, that is, the institutionalization of values (= social norms), law, rights, and membership in societal community. ${ }^{17}$ The integration of a society is a complementary process to its differentiation and the inclusion of the members of a society in a societal community is a matter of their socialization and their achievements, that is, their access to the social community. ${ }^{18}$

1. Eisenstadt has corrected this account of sociological theory.

Contrary, however, to the presupposition of classical evolutionary and structural functional analyses, different dimensions of structural differentiation and disembedment of cultural orientations and a growing problematization of the perception of the sources of human existence do not always go together and our reappraisal of the structural-evolutionary perspective on the development of human society stems from the recognition of this fact (Eisenstadt 1998: 30).

Structural differentiation does not lead to a higher dependency of the sectors of a society only, but thereby also a new problem of integration emerges in principle. In this evolutionary situation arises the need to regulate the relationship between the specialized sectors, as well as the distribution of free resources. There-

17. See a summary of his approach in Parsons 1967.

18. See on integration as participation (Parsons) and inclusion as modified conditions of the access to the systems of communication (N. Luhmann), in particular Lehmann 2002: 97-107. 
fore regulations by law and organizations are necessary as functional requirements of social interaction.

This is true inside of the Hobbesian problem of social order. This change goes along with a larger generalization of regulations and of trust. The constraint of the theory of structural differentiation and integration is that there is no simultaneous change of structure and institutions.

But a successful, orderly institutionalization of a new, more differentiated, social system is not a necessary outcome of every instance of social change or of increased social differentiation within a society. Moreover, the concrete contours of such institutionalization may greatly vary among different societies at similar or parallel stages of differentiation. The growth of systemic sensitivity to a broader and more variegated environment, to new problems and exigencies, does not necessarily imply the development, of the ability to deal with these problems, nor does it indicate the ways in which these problems may be solved. At any given level an adequate degree of integration, and the potentialities unfolded through the process of differentiation may be 'wasted' (i.e. fail to become crystallized into an institutional structure) (Eisenstadt 1965: 53-54). ${ }^{19}$

Call that the structural anomie of social change which is not to be eliminated by the evolutionary process and social order building. Eisenstadt examines macro-sociological change within the socio-structural evolution in the frame of the basic semantic maps and the components of institutional building.

A central aspect of such situations of change -especially of the more intensive area of macrosocietal change- is the continuous confrontation between different models and visions of social and cultural order and their different institution derivatives with the resources which are potentially available for new institutionaliza-

19. The concept of stage is used as a guide for the identification of the 'crucial breakthroughs' of different sectors of social and cultural activities from the ascriptive social framework. But therein the concrete crystallizations of this differentiation are not described or explained. Eisenstadt 1995: 122. 
tions. Such confrontation is articulated by the different elites and social groups which carry such models and attempt to institutionalize them. In such situation, different models of cultural and social order and different concrete institutional derivates thereof compete, as it were to became 'selected' and institutionalized in one of the concrete ways open to the given situation (Eisenstadt 1995: 380).

Social change in the socio-structural evolution is to systemize by the indetermination of the processes of communication, the construction of the cosmological and social order, as well as the disposal and the struggle over free resources. In this struggle a new formation of elites is continually effected.

2. Eisenstadt characterizes the initial level of socio-structural evolution with the distinction between congruent and incongruent societies. In the first case, the different elites and the components of the center are embedded in a social framework. In the second case, there is a differentiation between both and there are entrepreneurial personalities or groups. He compares this structural change to a mutation (Eisenstadt 1995: 132). This is of particular relevance to Eisenstadt and his evolutionary perspective, because the level of differentiation does not entail only one but many and competing possible orientations and potentialities for development. His distinction between structural differentiation and differentiation of the elite functions is a critique on the classical evolutionary approach. Eisenstadt's reappraisal of the evolutionary perspective is that evolutionary considerations indicate ranges of possibilities and types of potential breakthrough. The degree of differentiation within a given society (or intuitional field) does not determine the concrete contours of its structure intrinsically.

3. Finally, Eisenstadt and L. Roniger connect the analysis of differentiation with the investigation of social stratification and the patron-client relationship as a model of the structuring of the relationship between general and specific exchange as a 
regulation of the flow of resources between the members of various social groups. The analysis is of particular interest for the investigation of social structure, because this relation structures social exchange and is relevant for the institutionalization of trust and the belief in social order (Eisenstadt 1971, Eisenstadt \& Roninger 1984, Eisenstadt 1995: 202-238).

Thus, from all the vantage points, the central problem at the core of the analysis of friendship, ritual personal and clientelistic relations in the one of the construction and institutionalization of trust and meaning in social order and the ambivalent attitude to such institutionalization that pervades these relationship (Eisenstadt \& Roninger 1995: 29).

The patronage is a connection between agency (creativity) und structure and between culture and social-structure. Its analysis is informative for the formation of social order, about the basic cultural orientation, the properties of elites, their access to markets, and the distribution of resources because in the socio-structural evolution (as a consequence of modernization) new elites are formed, elites that dispute about available resources.

The core of Eisenstandt's sociology is that there are in all societies structural tensions in the construction of meaning which defines the conditio humana and the condition of membership in social systems. These are tensions between the cosmological order and its relation to the mundane world and the meta-thinking, the construction of social order and the relation between trust and meaning. They take effect in the relation between hierarchy and equality, solidarity (the distribution of resources), participation and the restrictions of organization.

The central part of organization is the construction of boundaries of collectivities which entails the access to the institutional marked. Thereby the regulation of this access is decided by the encoding of membership and the struggle over free resources. Both are evolutionary universals in the socio-structural evolution which exist in the structuration of preconditions (structure) and agency (creativity) only. The process of change happens by the 
confrontation of different visions and models of cultural and social order by the claims of social groups (elites) to institutionalize selected readings of these visions of model and new ground rules. Eisenstadt's view is that structural evolution is not a development of an evolutionary potential of human mankind and world history does not happen in potential universal stages. Western modernity is also not caused inevitably by the European Axial culture. Structural change depends on historical (contingent) events and factors.

The recreation of societal communication entails that the existential situation is constantly re-interpreted with respect to core symbols, ontologies, projects of social order and regulations. This basic condition causes consecutively new borderlines of communication. This leads to the argument that as the complexity of social systems increases, their integration by shared social norms becomes more improbable. But membership in social systems is the result of struggles and conflicts which are motivated also by cosmological visions, prestige, and also by the disposition of means of violence, as well as economic and technical resources. Inspired by M. Weber's Sociology of Religion, Eisenstadt considers the different constellations (configurations) in the socio-structural evolution as the leading subject of comparative historico-sociological investigations.

\section{Multiple Modernities and Axial Civilization}

(a) Modernity, Modernization, Modern, and Modernism

Some terminological distinctions would be helpful to characterize multiple modernities. One has to distinguish between modernity, modernization, the modern, and modernism. ${ }^{20} \mathrm{~A}$ brief descrip-

20. On these distinctions, see mainly Preyer 2006: 145-155; on the paradoxes of moral modernization, Preyer 2006: 140-43, on the distinction between postmodern, postmodernism and postmodernity and the revisions of modernity, Preyer 2006: 155-178. See also Turner 1992. 
tion of the terms mentioned above is given in the following passages.

Modernity is used for the characterization of the sociostructural innovations in the spheres of economics, politics and the legal systems as well as in the communities and scientific social systems. These innovations are the functional differentiation that occurred in Old Europe and throughout its history. This is the classical sociological attitude.

Modernization is used when referring to a process which is determined by place and time and has to be understood as a unique evolutionary direction which leads to a modern cultural and societal innovation. This process is characterized by a long lasting structural tendency. Classical sociology has systematized this structural change as a differentiation of action systems, structural differentiation and the emergence of a global world system which itself emerged from evolutionary universals. The theory of modernization was systematized by American sociologists after World War II, who stand more or less in the tradition of Weber.

The Modern describes the distinction of the contemporary and the old, e.g. modern art, literary, economics and so on. This expression is also used with an evaluative intent. It has been in use since the second half of the 18th century. In the mid-19th century the term 'modern times' was re-interpreted as a new epoch and led to a new collective identity which was independent of the status of the members within a social system and within social stratification. It was the classical period of modernity between the French Revolution and the end of World War I which put an end to the bürgerliche Gesellschaft and the end to the modern national state which had emerged from, and had been structured by the international political system since the mid-18th century in Europe. Since the mid-19th century, the Modern has been used synonymously with the West. This geographical metaphor served as a broad classification of Western Civilization in a rhetorical manner and in an intentional way. It also plays a significant role in highlighting differences and con- 
flicts between cultural, political and economic systems and communities, for example, the West versus the East, the South, South-East Asia, or Central Europe.

Modernism is used to characterize the intellectual social movement and attitude of the so-called avant-garde, from the late 19th century until the 1930s. At the same time, counter movements in culture and politics have also played a significant role. When referring to Modernism, the modern epoch is a description of the autonomy and the abstraction of science, art, law, and social coherence. The classical sociologist Durkheim and in particular Weber have analyzed modernity and modernization by the cultural and institutional factors and constellations which come together historically in Europe. They assumed more or less that this cultural program would be adopted globally in the process of Westernization. The extension of education, modern means (technology) of communication, the individualist orientation, and economic rationality take effect in most societies.

Modernism as a world culture has spread since the beginning of the 20th century. Modernity has influenced the most institutional domains of societies. But in the process of modernization since the mid-19th century, after World War II and in the contemporary scene of most societies, the anti-modern political movement has reacted against the structural change of modernization with different interpretations of modernity, like, for example, the reformist, the socialist, and the nationalist movement, and also contemporary fundamentalism.

\section{(b) The Notion of Multiple Modernities}

When looking back in time, we find evidence that there is a broader variability of and more alternatives to modernization than the classical theory, and also some of the contemporary theories of modernity and modernization, assume. Eisenstadt's notion of multiple modernities is a critique on the understanding of modernity of the grounding fathers of sociology and on the classical theory of modernization which was initiated by M. Weber. 
The notion of 'multiple modernities' denotes a certain view of the contemporary world -indeed of the history and characteristics of the modern era- that goes against the views long prevalent in scholarly and general discourses. It goes against the view of the 'classical' theories of modernization and of the convergence of industrial societies prevalent in the $1950 \mathrm{~s}$, and indeed against the classical sociological analyses of Marx, Durkheim, and (to a large extent) even of Weber, at least in one reading of his work. They all assumed, even if only implicitly, that the cultural program of modernity as it developed in modern Europe and the basic institutional constellations that emerged there would ultimately take over in all modernizing and modern societies; with the expansion of modernity, they would prevail throughout the world (Eisenstadt 2002). ${ }^{21}$

Modernization is not a set of fixed patterns of structural changes. This emerged out of Eisenstadt's research on comparative macro-sociological studies. His analysis started with the political systems of empires. This analysis has led to a critique by Eisenstadt of the classical theory of modernization and results in an initial Research Program in this specific field of sociological research on comparative civilizations in 1986 (Eisenstadt 1986). The core of this program was that the construction of boundaries was essential for social systems and for their selfselection within their environments, as well as for collectivities, organizations and the conditions of human life. These boundaries delineate the relations of the social systems with their environments. When we look at the beginnings of Eisenstadt's research and its elaboration throughout the research and the theorization in the Research Program of 1986, we can see that the re-systematization and the correction of the classical theory of modernity in the framework of multiple modernities is the immediate result of his work.

Eisenstadt systematizes with the notion of multiple modernities the different constellations between agency (creativity)

21. For an overview, see Eisenstadt 2004: 20-56. On Weber, see Preyer 2010. 
and structure and between culture and social-structure, as well as the role of elites within the expansion of the cultural visions in the socio-structural evolution. Modernization as a multiple modernization is a social change which goes back to the Axial-civilizations.

The Axial age civilizations provide an unusually instructive arena for the examination of both the difference between structural differentiation and the differentiation of elite activities -as well as of the variety of possible elite coalitions bearing different cultural visions of orientation. They facilitate an analysis of the impact of these elite coalitions and counter-coalitions on the institutional structure of their respective societies, on the modes of structural differentiation, and on the dynamic of these societies. Above all, the analysis of the Axial civilizations provides an arena for a most fruitful analysis of the relation between cultural, civilizational visions and institutional formations, for an analysis of the interweaving of cultural and social structural dimensions in the construction of such formations (Eisenstadt 1998: 39).

From the theoretical point of view, the Axial civilization is relevant for the basic characteristic of noncongruent societies. The research places emphasis on the autonomous cultural elites because the dynamic of these civilizations is initiated by them as articulators of the solidarity and trust within different collectivities. The evolutionary result of this change was new types of conflict between the social groups: the traditional group conflicts was transformed in political and ideological conflicts and the cult conflicts in embedded societies was transformed in the struggle between orthodox and heterodox interpretation of the 'transcendental sphere' of human and social condition.

Theoretically, multiple modernities do not represent a type of sociology that enumerates historical events; it is a multi-dimensional theoretical description of structural evolution. Multiple modernities do not assume that global modernity is derived from the West as a single pattern and does not describe a plurality of societal structures. Multiple modernities are to be understood as a critique of the classical theory of modernization. 
We have evidence that modernization does not lead to a unification and convergence of social structures. Therefore, modernization is neither a way towards evolutionary universals, nor is it based on them. Multiple modernities represent a structural change that continuously modifies belief-systems and their implementation in a process of translation and social interaction. There are many modernities, not only one single pattern of modernization. Paradigmatically, the relationship between Axial civilizations and modernity is re-systematized. Comparative research shows that modernity does not inevitably emerge from the European Axial Civilizations. Structural evolution shows -when modernization has begun by structural differentiationthat there are multiple Axial civilizations and multiple modernities. This is the reason why it is a new theory of modernity.

In socio-structural evolution, the First Axial Age (civilization) is a structural innovation. ${ }^{22}$ Thereby is initiated the differentiation between the poles (axes) of culture and social-structure which reorganizes the semantic mapping. This age is the key for the evolutionary investigation of societies because it is the socio-structural breakthrough of a political and religious center of a society which initiates a new problem of social integration which is not to remove in the socio-structural evolution of societies.

The structural change was initiated by the connection between both tendencies: 1. It emerged as the principal distinction between the transcendental and the mundane world and the problematization of the conceptions and premises of cosmological and social orders by growing reflexivity (second-order thinking). This leads to the problem of bridging the gap be-

22. The term goes back to Jaspers 1953 [1949], and refers to the civilizations emerged in ancient Israel, in ancient Greek, in Christian settings, partially in Zoroastrian Iran, in China's early imperial period, in Hindu and Buddhist South and Southeast Asia and in the Muslim world. Schwartz 1975: 1-7, Eisenstadt 1982: 294-314, Bellah 2005: 69-89, Eisenstadt 1986, 1987, 1992, Arnason, Eisenstadt \& Wittrock 2005, Arnason 2005: 19-49, Eisenstadt 2000b: 1-21, Eisenstadt forthcoming. 
tween different levels of reality which was assumed. 2 . There is a tendency for the disembedment of social interaction and its organization from the ascriptive complex of particular kinship and territorial frameworks. The development of free recourses and their organization leads to differentiated and complex social systems which created potential challenges of established institutional order. In this context, Eisenstadt analyses protest and social change in the framework of socio-structural evolution and the search of new models of social order which have as their foundation the difference between the transcendental dimension and the mundane life. Thus a potential universal orientation emerged, in contrast to the archaic thinking and a hierarchy of ontological levels of reality which implies an ontological subordination of the lower to the higher level. This goes along with the claim that the leading principles of the cosmological order are an orientation of the ongoing lifestyle.

It should be stressed that the structural changes of the institutional formation of the Axial civilizations established a new type of societal center. It is the place of the charismatic dimension of human existence and represented the transcendental vision of ultimate reality. Thereby is transformed the collective identity of the members of society and the institutional order. It created a new civilizational collectivity which is distinct form the primordial, ethnic and local collectivities. This initiated various reconstructions and transformations of different collectivities, that is, of the relationship between agency, culture and social structure. It is a feature of the Axial civilizations that new autonomous status groups make their appearance, for example, the ancient Israelic prophets and priests, Greek philosophers and sophists, the Hindu Brahmins and Chinese literati and their precursors. These are new types of religious and cultural activists which need to be distinguished from ritual and magical experts in pre-Axial civilizations. These groups are of particular interest for Eisenstadt's analysis of the role of autonomous intellectuals in the structural evolution. With the institutionalization of the Axial cosmology, a continuous change of the leading 
social and political elites is initiated which becomes a more autonomous place spreading its vision.

The Axial civilizations were crystallized by different institutional structures which did not manifest themselves as a particular stage in evolutionary change automatically. The change goes along with conflicts and struggles between and among the active groups and their visions and adaptive strategies. This is a typical feature of the Axial civilizations in general. In particular, what is constituted here is the long-lasting macro-structural change of the confrontation of different visions and arrangements of cultural and social orders with the struggle and concurrence about the resources which are available for institutionalizations. From Eisenstadt's viewpoint, structural evolution implies the openness of the historical situation at the same time on any stage. Therefore socio-structural evolution means the implementation of particular institutional structures and this has initiated continuous contestations.

Eisenstadt probes the Western modernity as the Second Axial Age which goes back to the First Axial Age. He exemplifies by his case studies of India, China, Israel, North America, Western Europe, the Ottoman Empire, as well as between a comparison of Western and East Europe and the non-axial culture of Japan, the structure of collective identities, the various centreperiphery formations, the patron-client relations and modern social movements. He characterizes the transition from the European Middle Age to the Western Modern Era as the change from collective identities to the modern society. In particular he emphasizes the role of religious groups for the socio-structural breakthrough which initiated a new centre-periphery constellation as a characterization of modern society. Eisenstadt has distinguished different historical formations within structural evolution:

1. They are structured by the basic premises of cosmic and social order, and these cosmologies exist in these societies as their orthodox and heterodox interpretations. This process is crystallized throughout their history. 
2. There is a pattern of institutionalizations that develops in the course of their history caused by their experience and through their encounter with other civilizations.

3. There are basic internal tensions, dynamics and contradictions caused by demographic, economic and political changes, and they are accompanied by the institutionalization of modern frameworks.

4. The different programs of modernity are formed by the encounter and interaction of the abovementioned processes. The result of these interactions determines the way in which civilizations and societies position themselves in an international system, and thus how their structural evolution takes place in a global system.

5. In European history, structural evolution leads to the modern European state system. It crystallized in a world-system that was first shaped in the 17th and 18th centuries.

6. Shifts of hegemonies take place in the different international state systems, and they are caused by economic, political, technological, and cultural changes.

7. In structural evolution, confrontations of modernities are caused by their expansions as the unfolding of a process which goes back to the Axial civilizations. This is a result of their basic premises and their institutionalizations which emerged in Western and Northern Europe and other parts of Europe and later in the Americas and Asia (in the Islamic, Hinduist, Buddhist, Confucian and Japanese Civilizations).

For the core of the research program of multiple modernities, the question is not what world religions and cultural religions in particular, contribute to the differentiation of modern market systems, occupations and their social regulations and institutions, but what they contribute to a changed framework. Here, the frame of reference is the special nature of civilizations with their own concepts of rationality, and how heterodoxies and sect movements affect the dynamics of structural change. Therefore, the distinction between the European (Western) original 
modernity and the token of later modernities is significant in this framework, as the later modernizations did not happen under the same conditions that caused the first. ${ }^{23}$

The dynamics of the divergent types of modernization was a process of social revolutions and the paradoxes of the modern cultural program that is shown by their continuous institutionalization. The antinomies (tensions, paradoxes) of the cultural program of Western modernity which are inherent from its beginning are: 1 . between totalizing and pluralistic interpretation of it components, 2 . between reflexivity and active construction of nature and society, 3 . between different evaluations of the major dimensions of human experience, and 4 . between control and autonomy (Eisenstadt 2004: VI-IX, 30-38). ${ }^{24}$ Typical for Western modernity is a radical switch of the political orders and their premises, the constitution of the political system and its legitimation, and the political process and its organization.

This is the place where Eisenstadt locates the research of social movements and their function in the process of Western modernization. Fundamentalist movements against modernity are involved in the structural change caused by the Western processes of modernization that we have learned from Parson's sociology. Protestantic fundamentalism, fascism, communism and contemporary Islamic fundamentalism are particular responses against the process of modernization standing in the context of modernity; they are not pre-modern or traditional social movements themselves. ${ }^{25}$

23. The distinction is relevant for Eisenstadt's (and W. Schluchter's) reinterpretation of M. Weber's analysis of occidental rationalism and European societal history (Gesellschaftsgeschichte). Weber has not analysed the later modernities. On a resystematization of Weber's sociology of religion with respect to the later modernities, see Münch 1986.

24. On the paradoxes of the modern cultural program, see Münch 1992: 27-48, Preyer 2006: 156-167; on the revisions of modernity, Preyer 2006: $167-178$.

25. On the protest movements in the United States of America, Japan, and fundamentalism as a social movement against modernity, see Eisenstadt 2000a; on fundamentalism, see Eisenstadt 2003: 937-951. 
In particular, communism was a modernist project. But in a comparative evolutionary perspective, these movements are similar to religious movements. Their program is the religious control of total society, as, for example, historical Islam, because Mohammed, God s own prophet, became the religious and political leader of the Arab community and at the same time of the community as a whole that was formed exclusively by the law of God as written in the Koran. This is exactly the specific difference in the construction of Medieval Christianity that must be characterized in terms of evolution by a structural differentiation between the church and the state. Neither of them is a politically organized society.

The classical period of modernity from the great revolutions to the First World War was a reconstruction of the political system focused on the nation-state and the revolutionary state. This established a new membership condition for the political system and the participation in societal communication. The institutionalization of the nation-state implies a unification of the cultural and the political identities of territorial population, while the center established a strict symbolic and affective commitment to the political order and spread it among the population with a more primordial characterization of the identity of the members of society. But in most modern societies there was a general civilizational orientation. ${ }^{26}$ A paradigmatic example was the American 'manifest destiny' since the 1840s. Eisenstadt emphasizes that the implementation of the cultural program has caused not only the vision of a pluralistic society but also a totalitarian Jacobin program. Communism, fascism and fundamentalism are the three Jacobin social movements which are involved in Western modernization (Eisenstadt 1996: 155-170). ${ }^{27}$ Therefore the modern political program implies a tension between its utopian and its civil component. The tension between the totalistic and

26. A partial exception is modern Japanese society.

27. On the role of revolutions, fundamentalism and social movements, see Preyer 2011: 159-189, Münch 1995a: 36-54, 1995b: 55-76. 
the pluralistic version of the political takes also effect in collective identities and their construction as primordial, civil and universalistic community, that is, as a homogeny or a heterogenic universe of the social.

The self-perception of society as modern, that is, as a distinct cultural and political program and in relation to other societies, is a feature of modernization which historically emerged in different societies like, for example, in Europe, Japan, and China. Therefore, modernity re-interprets the paradigm of structural social change from within, but not as a universalization or a generalization of the social pattern of European modernization. Theoretically, the translation and re-interpretation of cultural and social articulations of members of social systems come into play when multiple modernities are systematized.

The research on social movements in the paradigm of multiple modernities has a further sociological significance in the research of structural change which is re-described as modernization. ${ }^{28}$ Structural social changes restructure collective identities. In some cases, this process leads to more abstract identities like, for example, universalistic orientations of human rights and civic patterns of behavior of the higher education elites in the West. However, primordial solidarities and identities do not disappear. Collective identities like ethnic, national, religious, civilizational and ascriptive solidarities of different, regional identification are elementary social relationships of the cohesion of the members of social systems, all defined by membership conditions. This is not a contingent fact, nor is it epiphenomenal as is often argued, but it evolved in continuation from the delimitation of the expansions of social systems. This also helps us explain the significant role which religious movements play, not only in the processes of modernizations in the past, but also in the contemporary scene.

28. On a systematization of social movements in the context of the paradigms of modernization, see Preyer 2008: 259-288. 
The social construction of collective identities and borderlines indicates the condition of membership in social systems and is a symbolic and organizational construction of the borderlines of the collectivities within social systems of different sorts. Within this frame of reference of sociological theory, we need to explain charismatic activities that we ascribe to elite members as single persons or groups. The combination of collective identity and membership is coded as membership condition, and the range of the membership code fixes the participation in the relevant collectivity. The constructed social properties define the pattern of behavior, like, for example, a bad guy, a good Confucian, a civilized member, and the like. These evaluations of social properties, as well as natural ones, like gender, generation, kinship, territory, have a social function because they determine the borderline between in- and outsider on different levels of social status and, at the same time, the exclusion of the members of social systems. In this context, one must mention the research of D. N. Schneider and R. T. Smith on the function of the coding of similarities of members as conditions of participation in different collectivities, that is, fixing the relationship to other collectivities and their members, something that tends to be forgotten in the sociological community of investigators (Schneider \& Smith 1979).

The conclusion of Eisenstadt's comparative investigations on contemporary societies is that modernity and Westernization are to be distinguished because there is no single version of modernity. It is not to expect that Western modernization will happen again. ${ }^{29}$

29. Eisenstadt's List of Publications 1947-2009 is published in the announcement of Preyer 2011 on the homepage VS Verlag Sozialwissenschaften, Wiesbaden. 


\section{References}

Arnason, J. P. (2005). 'The Axial Age and its Interpreters. Reopening a Debate', in J. P. Arnason, S. N. Eisenstadt \& B. Wittrock (eds.), Axial Civilizations and World History, Leiden.

Arnason, J. P., Eisenstadt, S. N. \& Wittrock, B. (eds.) (2005). Axial Civilizations and World History. Leiden.

Bellah, R. N. (1957). Tokugawa Religion. Glencoe.

Bellah, R. N. (2005). 'What is Axial about the Axial Age?', European Journal of Sociology 46: 69-89.

Ben-Rafael, E. \& Sternber, Y. (2005). 'Social Change: Contribution of S. N. Eisenstadt', in Encyclopaedia of Sociology, Vol. 9, Oxford.

Black, C. E. (1966). The Dynamics of Modernization. A Study in Comparative History. London.

Eisenstadt, S. N. (1963). Political System of Empire. New York.

Eisenstadt, S. N. (1965). Essays on Comparative Institution. New York.

Eisenstadt, S. N. (1971). Social Differentiation and Stratification. Glenview.

Eisenstadt, S. N. (1971).'The Embedment of the Political in Social Structure in Primitive Societies', in S. N. Eisenstadt (ed.), Political Sociology. New York.

Eisenstadt, S. N. (1978). Revolution and the Transformation of Societies. New York.

Eisenstadt, S. N. (1982). 'The Axial Age. The Emergence of Transcendental Visions and the Rise of Clerics', European Journal of Sociology 23: 294-314.

Eisenstadt, S. N. (1986). A Sociological Approach to Comparative Civilizations: The Development and Directions of a Research Programm. The Harry S. Truman Research Institute for the Advancement of Peace, Department of Sociology and Social Anthropology, Jerusalem [rep. 2004, in ProtoSociology 24: Shmuel N. Eisenstadt: Multiple Modernities-A Paradigm of Cultural and Social Evolution, 260-317].

Eisenstadt, S. N. (1989). 'Cultural Premises and the Limits of Convergence in Modern Societies: An Examination of Some Aspects of Japanese Experience', Diogene 147: 125-140. 
Eisenstadt, S. N. (1990). 'Patterns of Conflict and Conflict Resolution in Japan: Some Comparative Indications', in S. N. Eisenstadt \& E. Ben-Ari (eds.), Japanese Models of Conflict Resolution. London.

Eisenstadt, S. N. (1994). 'Japan: Non-Axial Modernity and the Multiplicity of Cultural and Institutional Programs of Modernity', in J. Kreiner (ed.), Japan in Global Context, Papers Presented on the Occasion of the Fifth Anniversary of the German Institute for Japanese Studies, Philipp-Franz-von-Siebold Stiftung, Tokyo. Eisenstadt, S. N. (1995). Power, Trust, and Meaning. Essays in Sociological Theory and Analysis. Chicago.

Eisenstadt, S. N. (1996). 'The Jacobin Component of Fundamentalist Movements', Contention 5 (3), 155-170 [rep. 2003, in Comparative Civilizations and Multiple Modernities II., Leiden].

Eisenstadt, S. N. (1998). 'Social Division of Labor, Construction of Centers and Institutional Dynamics. A Reassessment of the Structural-Evolutionary Perspective', in G. Preyer (ed.), Strukturelle Evolution und das Weltsystem. Theorien, Sozialstruktur und evolutionäre Entwicklungen. Frankfurt a. M.

Eisenstadt, S. N. (2000a). Die Vielheit der Moderne. Weilerswist.

Eisenstadt, S. N. (2000b). 'The Civilizational Dimension in Sociological Analysis', Thesis Eleven 62: 1-21.

Eisenstadt, S. N. (2002). 'Multiple Modernities', 1, in: Eisenstadt (ed.), Multiple Modernities. New Brunswick.

Eisenstadt, S. N. (2003a). 'Introduction: Comparative Studies and Sociological Theory. From Comparative Studies to Civilizational Analysis: Autobiographical Notes', in Comparative Civilizations and Multiple Modernities I. Leiden.

Eisenstadt, S. N. (2003b). 'Multiple Modernities', in Comparative Civilizations and Multiple Modernities II. Leiden.

Eisenstadt, S. N. (2004). 'Multiple Modernities: The Basic Framework and Problematic', in ProtoSociology 24: Shmuel N. Eisenstadt: Multiple Modernities-A Paradigm of Cultural and Social Evolution.

Eisenstadt, S. N. (2006a). Die großen Revolutionen und die Kulturen der Moderne. Wiesbaden.

Eisenstadt, S. N. (2006b). 'Die protestantische Ethik und der Geist des Kapitalismus. Eine analytische und vergleichende Darstellung', in Theorie und Moderne. Soziologische Essays. Wiesbaden. 
Eisenstadt, S.N. (2009). 'Cultural Programmes, the Construction of Collective Identities and the Continual Reconstruction of Primordiality', in G. Preyer (ed.), Neuer Mensch und kollektive Identität in der Kommunikationsgesellschaft. Wiesbaden.

Eisenstadt, S. N. (forthcoming). 'The Axial Conundrum. Between Transcendental Visions and Vicissitudes of their Institutionalizations: Constructive and Destructive Possibilities'.

Eisenstadt, S. N. (ed.) (1986). The Origins and Diversity of Axial Age Civilizations. New York.

Eisenstadt, S. N. (ed.) (1987). Kulturen der Achsenzeit I. Ihre Ursprünge und ihre Vielfalt. Frankfurt a. M.

Eisenstadt, S. N. (ed.) (1992). Kulturen der Achsenzeit II. Ihre institutionelle und kulturelle Dynamik. Frankfurt a. M.

Eisenstadt, S. N. \& Giesen, E. B. (1995). 'The Construction of Collective Identity', European Journal of Sociology, 36: 72-102. Eisenstadt, S. N. \& Roninger, L. (1984). Patrons, Clients and Friends. Interpersonal Relations and the Structure of Trust in Society. Cambridge.

Eisenstadt, S. N. \& Roninger, L. (1995). 'Patron Client Relation as a Model of Structuring Social Exchange', in Power, Trust, and Meaning.

Giddens, A. (1979). Central Problems in Social Theory. Cambridge. Giddens, A. (1984). The Constitution of Society. Outline $f$ the Theory of Structuration. Oxford.

Jaspers, K. (1953 [1949]). The Origin and Goal of History, London. Lehmann, M. (2002). Inklusion. Beobachtung einer sozialen Form am Beispiel von Religion und Kirche. Frankfurt a. M.

Levi, M. J. (1966). Modernization and the Structure of Society. A Setting for International Affairs. Princeton NJ.

Mayer, E. (1976). Evolution and the Diversity of Life. Cambridge. Münch, R. (1986). Die Kultur der Moderne (2 vols.), vol. 1 Ihre Grundlagen und ihre Entwicklung in England und Amerika, vol. 2 Ihre Entwicklung in Frankreich und Deutschland. Frankfurt a. M.

Münch, R. (1992). Dialektik der Kommunikationsgesellschaft. Frankfurt a. M.

Münch, R. (1995a). 'Soziale Bewegungen I: Zwischen Moderne und Antimoderne', in Dynamik der Kommunikationsgesellschaft. Frankfurt a. M. 
Münch, R. (1995b). 'Soziale Bewegungen II: Die Dialektik von Fundamentalismus und Moderne', in Dynamik der Kommunikationsgesellschaft. Frankfurt a. M.

Myrdal, G. (1998 [1944]). An American Dilemma: The Negro Problem and Modern Democracy. New Brunswick NJ.

Nederveen Pieterse, J. (2001). Development Theory. Deconstruction/Reconstruction. London.

Parsons, T. (1967). 'Evolutionary Universals in Society', in T. Parson s, Sociological Theory and Modern Society. New York.

Preyer, G. (1998). 'Mitgliedschaftsbedingungen. Zur soziologischen Kerntheorie einer Protosoziologie', in G. Preyer (ed.), Strukturelle Evolution und das Weltsystem. Theorien, Sozialstruktur und evolutionäre Entwicklungen. Frankfurt a. M.

Preyer, G. (2006). Soziologische Theorie der Gegenwartsgesellschaft (3 vols.), I: Mitgliedschaftstheoretische Untersuchungen. Wiesbaden.

Preyer, G. (2008). Soziologische Theorie der Gegenwartsgesellschaft (3 vols.), III: Mitgliedschaft und Evolution. Wiesbaden.

Preyer, G. (2010). Max Webers Religionssoziologie. Eine Neubewertung. Frankfurt a. M.

Preyer, G. (2011). Zur Aktualität von Shmuel N. Eisenstadt. Einleitung in sein Werk. Wiesbaden.

Schneider, D. M. \& Smith, R. T. (1979). Class Difference and Sex Role in American Kinship and Family Structure. Englewood Cliffs. Schwartz, B. I. (1975). 'The Age of Transcendence', Daedalus 104.2: 1-7.

Sewell, W. (1992). 'A Theory of Structure: Duality, Agency, and Transformation', American Journal of Sociology, 98: 1-29.

Turner, B. S. (ed.) (1992). Theories of Modernity and Postmodernity. Sage (CA).

Weber, M. \& Shils, E. (1975). Center and Periphery. Chicago. Weiner, M. (1966). Modernization. The Dynamics of Groth, Voice of America Forum Lectures. 